\title{
Diet of the gracile mouse opossum Gracilinanus agilis (Didelphimorphia: Didelphidae) in a neotropical savanna: intraspecific variation and resource selection
}

\author{
Nícholas F. de Camargo • Juliana F. Ribeiro • \\ Amabílio J. A. de Camargo • Emerson M. Vieira
}

Received: 10 February 2013 / Accepted: 15 May 2013

(C) Mammal Research Institute, Polish Academy of Sciences, Białowieża, Poland 2013

\begin{abstract}
Investigation of the effect of endogenous and exogenous factors on the diet of animals is necessary for a better understanding of their feeding habits. This approach can provide relevant information on the autoecology of a species and its ecological interactions. We investigated the composition and intraspecific variation in the diet of the marsupial Gracilinanus agilis in areas of dry woodland forests (i.e., cerradão) in the Cerrado of Central Brazil, taking into consideration the availability of prey (arthropods) in the environment. We found insects, spiders, birds, and fruits in the scats of G. agilis. Insects (orders Hymenoptera, Isoptera, Hemiptera, and Coleoptera) and fruits were the most frequently consumed resources. Males fed more heavily on insects than females did, whereas during the warm-wet season (October to April), the reproductive females fed on insects more than the nonreproductive females did. On the other hand, the consumption of fruits and vertebrates did not vary between seasons, sexes, or according to female reproductive condition. Moreover, reproductive females fed more frequently on ants and beetles than nonreproductive females did. We
\end{abstract}

Cummunicated by: Rafał Kowalczyk

N. F. de Camargo • J. F. Ribeiro

Pós-graduação em Ecologia, Universidade de Brasília,

Brasília, Distrito Federal, Brazil

N. F. de Camargo J. F. Ribeiro $\cdot$ E. M. Vieira $(\triangle)$

Laboratório de Ecologia de Vertebrados,

Departamento de Ecologia, Instituto de Ciências Biológicas,

Universidade de Brasília (UnB), CP 04457 ,

Brasília, Distrito Federal 70919-970, Brazil

e-mail: emvieira@unb.br

A. J. A. de Camargo

Embrapa Cerrados, Rodovia BR 020, km 18, CP 08223 ,

Planaltina, Distrito Federal 73310-970, Brazil also detected both positive (for Isoptera and Hemiptera) and negative (for Hymenoptera) selection of insects during the cool-dry season, whereas in the warm-wet season, these resources were consumed according to their availability in the environment. Our study revealed that $G$. agilis is an insectivore-omnivore species, but fruits also are a relevant part of its diet. This marsupial seemed to select their prey qualitatively according to its energy demands and nutritional requirements.

Keywords Cerrado $\cdot$ Diet $\cdot$ Marsupial $\cdot$ Insects $\cdot$ Resource selection

\section{Introduction}

Knowledge about the diet of wild animals is essential for the understanding and interpretation of complex ecological issues, such as niche relationships, competitive processes, coexistence, and predation (e.g., Greene and Jaksic 1983; Jones and Barmuta 1998; Vieira and Port 2007), as well as the influence of species on ecosystems (e.g., Bourlière 1985; Covich et al. 1999 García et al. 2009; Cantor et al. 2010). This knowledge can also support actions for the conservation of target animal species (Rawlins and Handasyde 2002; Leiner and Silva 2007; Lessa and Costa 2010).

The diet of a species is the result of several factors, such as risk of injury, age, sex, seasonal variation, food availability, individual reproductive condition, and interaction with other species (Julien-Laferrière and Atramentowicz 1990; Hayward and Kerley 2005). The analysis of individual variations within a population is highly relevant because potential constraints on diet choice, such as available feeding time or nutrient requirements (Westoby 1974; Pulliam 1975; Belovsky 1978; Smith and Broome 1992), may differ 
among individuals. Consequently, it may be unrealistic to draw general conclusions about a species based solely on an average individual in a population (Ritchie 1988).

The feeding habits of didelphid marsupials vary along a gradient from species that are predominantly frugivorous (e.g., Caluromys philander) to species that show a high degree of carnivory/insectivory (e.g., Lutreolina crassicaudata) (Vieira and Astúa de Moraes 2003). Between these two extremities are species that are more omnivorous, such as opossums, Didelphis spp., and several mouse opossums belonging to the genus Gracilinanus (Vieira and Astúa de Moraes 2003). However, few detailed studies investigated how endogenous (e.g., sex, age, and reproductive condition) and exogenous (e.g., availability of resources and seasonality) factors can directly affect the feeding habits of didelphids. Therefore, the general term "omnivory" can be misleading or at least insufficient (Martins et al. 2006) for such a diverse taxa. With regard to this group, this general classification might hide features related to the autoecology of the species and its interactions with the environment (Santori and Astúa 2006).

In comparison with studies on neotropical forests (e.g., Santori et al. 1995; Vieira and Izar 1999; Cáceres 2004; Martins and Bonato 2004; Leiner and Silva 2007), relatively few studies have evaluated feeding habits of marsupials in savannas, including the Brazilian Cerrado (however, see Martins et al. 2006; Lessa and Costa 2010; Bocchiglieri et al. 2010; Camargo et al. 2011). Harboring 251 mammal species, including 26 didelphids (Paglia et al. 2012), this large $\left(2 \times 10^{6} \mathrm{~km}^{2}\right)$ biome is the most threatened and richest tropical savanna on the planet (Myers et al. 2000; Klink and Machado 2005). The Cerrado dominium includes savannas, grasslands, and forests and is influenced by a highly seasonal climate with well-defined warm-wet and cool-dry seasons (Eiten 1972). These year-round changes in resource availability should be an important factor in the consumption pattern of food items by animals. Therefore, the evaluation of how this variation in resource availability affects prey consumption by marsupials in the Cerrado is a potentially relevant topic.

In the present study, we evaluated the dietary patterns of Gracilinanus agilis in the Cerrado of Central Brazil. Our main objectives were as follows: (1) to describe the diet composition of this species in areas of cerradão (dry woodland physiognomy of the Cerrado) in Central Brazil, (2) to evaluate patterns of intraspecific variation in the feeding habits of this marsupial related to sex and reproductive status, and (3) to assess seasonal variations in the diet of G. agilis related to the availability of arthropods in the environment. We predicted the following: (1) G. agilis feeds more intensively on insects (mainly termites, ants, and beetles) compared to fruits (Bocchiglieri et al. 2010; Lessa and Costa 2010) and (2) there are seasonal variations in food item consumption by G. agilis related to sex. Males feed more intensively on insects in the cool-dry season because of higher energy demands related to mate searching, whereas females feed more intensively on insects in the warm-wet season because of high-energy costs and protein demand during pregnancy and lactation (as suggested by Martins et al. (2006) for the congeneric Gracilinanus microtarsus). (3) There is higher consumption of fruits in the warm-wet season because this resource is more abundant during this period of the year (Batalha and Martins 2004), and (4) G. agilis acts as a generalist insectivore, consuming insect orders according to their availability in the studied environments.

\section{Methods}

\section{Studied species}

The agile mouse opossum $G$. agilis is a small (body mass= 20-30 g), nocturnal, and scansorial marsupial that occurs from the Panama-Colombia border to the northeast, midwest, and southeast of Brazil (Emmons and Feer 1990). It is generally common in gallery forests (evergreen vegetation that surrounds streams) and cerradão (savanna woodland forest) in the Brazilian Cerrado (Nitikman and Mares 1987; Lacher and Alho 2001). This marsupial has a marked seasonal pattern of reproduction: females give birth generally in the beginning of the warm-wet season (October to April) (Rossi et al. 2006).

\section{Study areas}

We gathered the field data in two different locations in the city of Brasilia in the Federal District of Brazil: the Jardim Botânico de Brasília (JBB, Botanical Garden of Brasília [15 $\left.52^{\prime} \mathrm{S}, 47^{\circ} 50^{\prime} \mathrm{W}\right]$ ) and the Fazenda Água Limpa (FAL, the ecological and agricultural field station of the University of Brasília [ $\left.\left.15^{\circ} 58^{\prime} \mathrm{S}, 47^{\circ} 59^{\prime} \mathrm{W}\right]\right)$. These two contiguous locations are part of a large legally protected area that covers about 15,000 ha of the continuous Cerrado vegetation. All trapping grids were located in areas of cerradão, a xeromorphic forestlike physiognomy of the Cerrado whose height of the tree layer varies from 8 to $15 \mathrm{~m}$, and the tree cover ranges from 50 to $90 \%$ (Ribeiro and Walter 1998). In the Cerrado, about 90 $\%$ of the annual precipitation of 1,100-1,600 mm occurs between October and April (Miranda et al. 1993).

\section{Trapping methods}

Animal captures took place from September 2009 to August 2010 using Sherman live traps placed in four grids (three grids located at JBB [JB1, JB2, and JB3] and one grid located at FAL) composed of $144(12 \times 12)$ capture stations spaced at $15-\mathrm{m}$ intervals. Each grid was sampled three times 
in each season during six consecutive nights, totaling 23,040 trapping nights. In each capture session and for each grid, we randomly selected 80 capture stations for placing traps on the ground and 80 capture stations for placing traps in the understory. We used as bait a uniform mixture of peanut butter, corn flour, mashed banana, cod liver oil, and vanilla essence.

We registered the sex and reproductive condition of each captured individual, which also received a numbered ear tag (National Band and Tag Co., Newport, KY, USA, Monel tag, size 1). The reproductive condition of the females was inferred from the swelling of the nipples (Pinheiro et al. 2002a). Because of inaccurate evaluation of male reproductive condition based on external characteristics (Quental et al. 2001), we did not evaluate this condition in the males.

Scat collection and identification of food items

We collected the scats directly from traps or during handling of the trapped animals. Each time an animal was captured, the trap was cleaned to avoid contamination of subsequent scat samples by other individuals captured in the same trap. The samples were stored in a refrigerator for preservation as well as the subsequent sorting and identification of food items (Casella and Cáceres 2006; Martins et al. 2006).

We washed each scat sample in two different superimposed sieve meshes ( 0.1 and $0.7 \mathrm{~mm}$ ) (Leiner and Silva 2007). With the aid of a binocular stereoscopic microscope, we categorized the food items into four food categories: arthropods, fruits (seeds, pulp, and fiber), vertebrates, and unidentified material. To ensure statistical independence of the samples, for the analyses, we used only one sample of each individual per season (warm-wet and cool-dry).

The frequency of food categories was determined by considering the occurrence of each item in relation to the total number of items found in all analyzed samples. To estimate the abundance of each food category, we used a grid with lines forming $0.25-\mathrm{cm}^{2}$ squares printed on a piece of paper, which was placed under a $10-\mathrm{cm}$-diameter Petri dish. We placed the fecal content diluted in water in this Petri dish and classified each food item that touched the intersection of the lines into one of the four main categories.

All food items found in the scats were identified using identification keys or by referring to fruits and arthropods collected in each studied area. By comparing items found in the scats with fruits collected in the field, we were able to detect not only seeds but also other remnants of fruit parts that generally are not easily identified in fecal samples, such as pulp and fibers. The occurrence of such structures in the fecal samples clearly indicated that the animals consumed fruits. Therefore, our efficiency in detecting this item in the samples was certainly high. In addition to this, the arthropod parts found in the scats were identified up to order level by one of the authors, a taxonomic specialist on insects (AJAC), by comparison with specimens stored at the Entomological Collection of "Embrapa Cerrados" (Center for Agricultural Research on the Cerrado). To avoid any bias in the identification of insect orders, we only analyzed recognizable structures such as heads, antennas, mandibles, wings, elytra, and/or legs.

Availability of arthropods

To estimate the availability of arthropods in the environment, we set 30 pitfalls at each grid in each capture session and activated them for three consecutive days. These traps consisted of 200-ml plastic cups buried with the opening flush to the ground surface. Each trap was filled with $50 \mathrm{ml}$ solution of formaldehyde, water, and drops of soap (to break the water tension). These pitfalls were arranged in three parallel transects that were randomly distributed within the grids. We identified the collected arthropods up to order level with the support of identification keys (Triplehorn and Johnson 2005) and also the Entomological Collection of Embrapa Cerrados. To estimate the availability of this resource, we measured the total biomass to the nearest $0.0001 \mathrm{~g}$ (dry weight) of each arthropod order per sampling session.

\section{Statistical analysis}

Preliminary statistical comparisons of arthropod availability (as response variables) with regard to the four most highly consumed orders by $G$. agilis indicated significant differences among areas (factorial multivariate analysis of variance [MANOVA] using 10,000 iterations: $F_{3,64}=4.468$, $P<0.001)$. However, a posteriori comparisons revealed that such difference was caused by the distinct availability of termites in just one of the sampled grids (JB3) in relation to the three remaining ones. Thus, for statistical analyses, we grouped the samples of G. agilis individuals captured in the four trapping grids for all the main insect orders except for termites. For this later order, we excluded all the JB3 data from the analysis, considering only the animals captured in the other three grids. Therefore, we were able to analyze the consumption patterns of the studied marsupial without concerns regarding potential biases caused by among-site differences in arthropod availability.

We evaluated potential differences in the relative abundance of each of the main food categories consumed using a factorial MANOVA by resampling with 10,000 iterations, considering sex and season as factors and the abundance of the main food categories (arthropods, fruits, and vertebrates expressed as the number of grid intersections covered by each category) as dependent variables. Because the reproductive condition was assessed only in females and only in the warm-wet season (we did not find any reproductive females outside this season), we compared the variation in 
abundance of food categories according to the single factor of reproductive condition, also performing a factorial MANOVA by resampling (10,000 interactions).

We also evaluated, specifically for arthropods (the most representative food category, see the "Results" section), the effects of sex, season, and reproductive condition on the occurrence of the main orders found in the scats. Since we could not accurately evaluate the abundance of each arthropod order consumed by each G. agilis individual, we considered the occurrence (i.e., presence or absence) of the order in fecal samples according to sex and season to perform a logistic regression analysis with two-way interaction terms (Hosmer and Lemeshow 1989) for each of the four most common arthropod orders (see the "Results" section). We again performed a distinct logistic regression analysis for evaluating changes related to the reproductive condition of the females. In this case, only this factor (reproductive or nonreproductive females) was considered. The analyses regarding resource availability, the relative abundance of food categories, and the frequency of arthropods in feces were performed using the software R 2.13.1 (R Development Core Team 2011).

We performed a chi-square test (Gibson 2001) to assess whether G. agilis consumed the arthropods according to their availability in the environment. The observed values were the total number of items of each of the four most common order found in all the fecal samples. We used the proportion of the total dry biomass (obtained with the pitfall traps) corresponding to each of these orders to calculate their expected values of consumption. We ran separate analyses for comparison between the observed and expected patterns of each sex during each of the two seasons and between reproductive and nonreproductive females during the warm-wet season.

\section{Results}

Overall patterns of G. agilis diet

We analyzed 422 samples ( 90 males and 90 females from the cool-dry season; 82 males and 160 females from the warm-wet season) from 337 individuals of G. agilis. Arthropods, which were present in $100 \%$ of the samples, were represented by nine orders of insects and one of arachnid. The most frequent orders were Hymenoptera (Formicidae only), Hemiptera, Coleoptera, and Isoptera (Table 1). All remnants of vertebrates consumed by G. agilis were identified as birds, which were recognized by feathers, bones, and eggshell fragments. Furthermore, we found high frequencies of fruits in the sampled scats of this marsupial. About $86 \%$ of the total samples contained seeds, fibers, and the pulp of three plant families (Table 1).
Table 1 Percentage of the total number of samples (in percent) and absolute frequency $(N)$ of food items detected in 422 scat samples of G. agilis in four areas of cerradão (closed woodland forest) located in Central Brazil (Brasília, DF)

\begin{tabular}{lll}
\hline Food item & Percent & Absolute frequency $(N)$ \\
\hline Fruits & & \\
Melastomataceae & $82.85(48.10)$ & $350(203)$ \\
Solanaceae & 15.59 & 66 \\
Viscaceae & 12.90 & 54 \\
Unidentified fruits & 4.26 & 18 \\
Arthropods & & \\
Arachnida & & \\
Araneae & 1.61 & 7 \\
Insecta & & \\
Hymenoptera & 60.96 & 257 \\
Hemiptera & 53.81 & 227 \\
Isoptera & 52.65 & 222 \\
Coleoptera & 8.54 & 36 \\
Lepidoptera & 5.31 & 22 \\
Orthoptera & 3.23 & 14 \\
Odonata & 0.92 & 4 \\
Diptera & 0.46 & 2 \\
Unidentified arthropods & 0.46 & 2 \\
Vertebrates & & 19 \\
Aves & 4.50 & \\
\hline
\end{tabular}

Also indicated are the number of samples containing only seeds (i.e., disregarding identified pulp and fibers of melastomes) and correspondent percentage (in parentheses). For the other two plant families, we considered only the presence of seeds. Unidentified fruit remains (pulp, fibers, or fruit peels) are indicated as "unidentified fruits"

We detected that males ( $n=172$ sampled individuals) fed significantly more on arthropods than females $(n=250)$ did (factorial MANOVA: $F=17.09, P<0.0001$ ). The species as a whole fed more intensively on arthropods in the cool-dry season $(n=180)$ than in the warm-wet season $(n=242$; $F=55.76, P<0.0001)$. Regarding the consumption of the other two feeding categories (fruit and vertebrates), we did not detect significant differences related to season or sex (Fig. 1). Our results also indicated a significant interaction between sex and season in relation to the consumption of arthropods $(F=76.090, P<0.0001)$. Males relied more on this resource in the cool-dry season, whereas females tended to maintain consumption steadily in the two seasons (Fig. 1). However, the analysis of the effect of the reproduction condition on female diet during the warm-wet season indicated a greater consumption of arthropods by reproductive females $(n=62)$ compared to the nonreproductive ones $(n=98)$ $(F=19.849, P<0.0001$; Fig. 1). On the other hand, regarding the consumption of the other two food categories - fruits and vertebrates - we did not detect significant differences between reproductive and nonreproductive females (Fig. 1). 


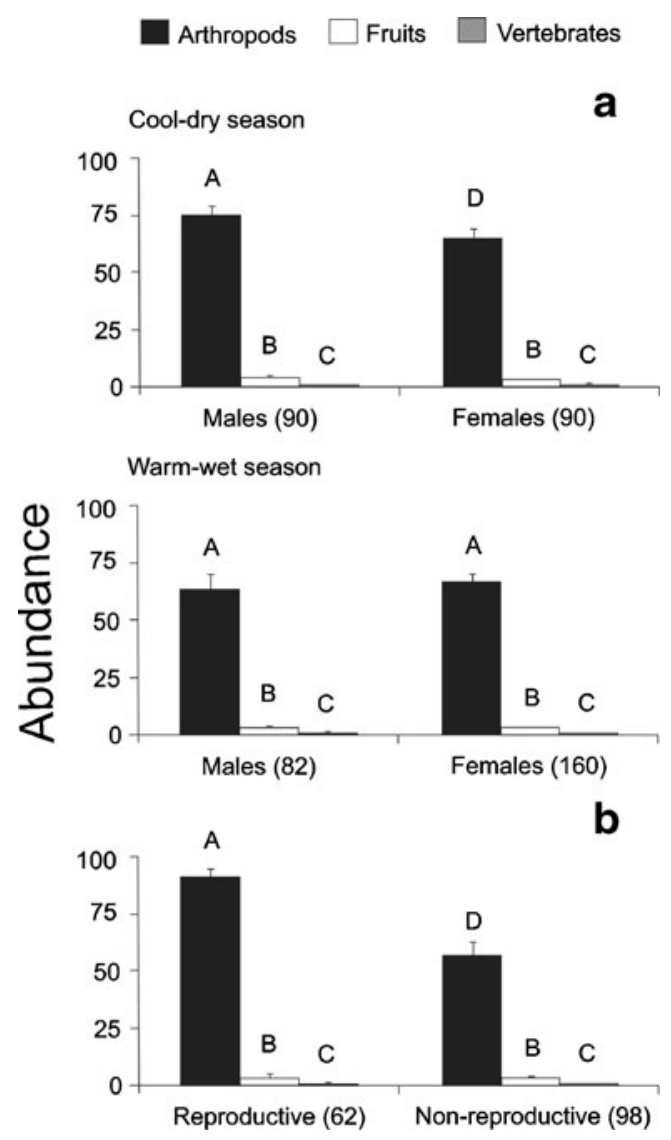

Fig. 1 Abundance of food items (expressed as number of grid intersections covered by each category observed under a stereoscopic microscope, see text for details) consumed by G. agilis according to sex and season $(a)$ and also to female reproductive condition only during the warm-wet season $(b)$. The error bars indicate the standard errors. The numbers in parentheses represent the total number of individuals analyzed. Distinct uppercase letters indicate significant differences $(P<0.05)$ between categories according to Tukey's post hoc test

Frequency of the most highly consumed insect orders

The logistic regression analyses indicated significant differences between seasons but no significant difference between sexes and no interaction between sex and season in relation to the most highly consumed insect orders. The orders Isoptera and Hemiptera were consumed more frequently in the cool-dry season than in the warm-wet season. However, the order Hymenoptera was more frequently consumed by G. agilis in the warm-wet season than in the cool-dry season (Table 2).

The comparison between reproductive and nonreproductive females did not show any significant effect of reproductive condition on the consumption of Isoptera and Hemiptera (Table 2). On the other hand, with regard to the other two orders, we detected that reproductive females fed more frequently on both ants and beetles compared to nonreproductive females (Table 2).
Arthropod availability

According to our data on arthropod availability in the environment, the orders that most contributed to the total dry biomass were Hymenoptera (percentage of total biomass $51.4 \%)$, Isoptera $(17.2 \%)$, Coleoptera $(9.3 \%)$, Orthoptera $(6.8 \%)$, and Hemiptera $(5.6 \%)$. The remaining arthropod orders represented less than $4 \%$ of the total dry biomass obtained with pitfalls. Our analysis of the availability of these four common insect orders most commonly consumed by G. agilis (see Table 1) showed between-season differences in the dry biomass (factorial MANOVA with 10,000 interactions: $\left.F_{1,64}=5.874, P<0.001\right)$. However, we found no interaction between the factors of area and season $\left(F_{3,64}=0.373, P=0.983\right)$. Moreover, further comparisons showed that only Coleoptera (Tukey's test, $P<0.001$ ) and Hemiptera $(P=0.002)$ differed in their dry biomass between seasons. Both orders presented lower dry biomass in the cooldry season (Coleoptera: $1.5 \%$ of total biomass, Hemiptera: $2.0 \%$ of total biomass) compared to the warm-wet season (Coleoptera: $14.4 \%$, Hemiptera: $8.0 \%$ ).

\section{Resource selection by G. agilis}

Our findings showed that selection of some insect orders by $G$. agilis differed in relation to sex, season, and female reproductive condition. Both males $\left(\chi^{2}=127.01, d f=2\right.$, $P<0.001)$ and females $\left(\chi^{2}=127.24, d f=2, P<0.001\right)$ positively selected (i.e., consumption was greater than expected) the order Hemiptera in the cool-dry season, but selected negatively the order Hymenoptera (i.e., consumption was lower than expected). Moreover, our analyses showed positive selection of Isoptera in this season for both males $\left(\chi^{2}=3.88, d f=1, P=0.048\right)$ and females $\left(\chi^{2}=4.06, d f=1\right.$, $P=0$. 040). In the warm-wet season, males $\left(\chi^{2}=6.82\right.$, $d f=2, P=0.033)$ and females $\left(\chi^{2}=10.87, d f=2, P=0.004\right)$ selected negatively the order Coleoptera and did not select any of the remaining insect orders analyzed (i.e., consumption did not differ from the expected). Additionally, reproductive females $\left(\chi^{2}=1.60, d f=2, P=0.450\right)$ did not select any of the orders examined, but nonreproductive females negatively selected beetles $\left(\chi^{2}=8.31, d f=2, P=0.015\right.$; Fig. 2$)$.

\section{Discussion}

Overall patterns of G. agilis diet

According to our results, $100 \%$ of the analyzed individuals fed on arthropods. The most abundant insect orders, Isoptera and Hymenoptera, were among the most consumed, which supported the general feeding strategy reported for G. agilis (Martins and Bonato 2004; Martins et al. 2006; Lessa and 
Table 2 Results of logistic regressions evaluating the effect of season (cool-dry $\times$ warmwet), sex, and female reproductive condition (FRC, reproductive females $\times$ nonreproductive females) on the occurrence of the four most common insect orders in the fecal samples of G. agilis in cerradão areas

The effect of female reproductive condition was evaluated only during the reproductive period (warm-wet season)

$* P<0.05$ (statistically significant values)

\begin{tabular}{|c|c|c|c|c|}
\hline & \multicolumn{4}{|l|}{ Insect order } \\
\hline & Hymenoptera & Isoptera & Hemiptera & Coleoptera \\
\hline \multicolumn{5}{|l|}{ Season (cool-dry) } \\
\hline Likelihood ratio & 12.960 & 30.109 & 267.400 & 1.897 \\
\hline Coefficient & -0.971 & 1.657 & 4.450 & -0.623 \\
\hline Odds ratio & 0.379 & 5.244 & 85.627 & 0.536 \\
\hline$P$ value & $<0.001 *$ & $<0.001^{*}$ & $<0.001 *$ & 0.168 \\
\hline \multicolumn{5}{|l|}{ Sex (males) } \\
\hline Likelihood ratio & 0.214 & 0.270 & 0.284 & 0.485 \\
\hline Coefficient & 0.140 & 0.154 & 0.173 & -0.308 \\
\hline Odds ratio & 1.150 & 1.166 & 1.189 & 0.735 \\
\hline$P$ value & 0.643 & 0.635 & 0.593 & 0.486 \\
\hline \multicolumn{5}{|l|}{ Season $\times$ sex } \\
\hline Likelihood ratio & 0.370 & 0.154 & 0.059 & 0.232 \\
\hline Coefficient & 0.259 & 0.196 & 0.212 & -0.391 \\
\hline Odds ratio & 1.296 & 1.217 & 1.236 & 0.676 \\
\hline$P$ value & 0.543 & 0.694 & 0.806 & 0.630 \\
\hline \multicolumn{5}{|c|}{ FRC (reproductive female) } \\
\hline Likelihood ratio & 4.075 & 0.092 & 0.071 & 6.364 \\
\hline Coefficient & 0.724 & 0.164 & 1.107 & 1.218 \\
\hline Odds ratio & 2.064 & 1.178 & 0.102 & 3.383 \\
\hline$P$ value & $0.043^{*}$ & 0.760 & 0.788 & $0.012 *$ \\
\hline
\end{tabular}

Costa 2010; Bocchiglieri et al. 2010). Termites and ants comprise two of the most abundant insect orders in the Cerrado (Pinheiro et al. 2002a) and represent a concentrated type of resource, thus being considered rewarding food items (Abensperg-Traun and Steven 1997). Indeed, consumption of this type of prey is common in other didelphid species (e.g., Santori et al. 1995; Lessa and Costa 2010; Pinheiro et al. 2002b).

In our study, approximately $86 \%$ of the sampled individuals fed on fruits (mainly from the Melastomataceae family), which is the highest proportion of fruit consumption ever recorded for this marsupial genus. We found pulp and fibers in high frequencies in the scats, and all these identifiable materials belonged to fruits of the Melastomataceae family. In fact, in the study area, G. agilis positively selects melastomes, feeding largely on and potentially dispersing Miconia species (Camargo et al. 2011). Contrary to our results, other field-based studies indicated that fruits are not a relevant component in the diet of Gracilinanus spp. (e.g., Martins and Bonato 2004; Martins et al. 2006; Bocchiglieri et al. 2010; Lessa and Costa 2010) but laboratory studies indicate a high consumption of fruits by G. agilis (Astúa de Moraes et al. 2003; Santori and Astúa de Moraes 2006). Fruit remnants in fecal samples can be underestimated because of the high digestibility of pulp (Caron et al. 1985; Astúa de Moraes et al. 2003) and by the act of seed spitting (Leiner and Silva 2007). As discussed in the "Methods" section, we identified remnants of fruit parts that generally are not easily identified in fecal samples, thus potentially increasing the relative importance of this group in the G. agilis diet.

We also verified the first occurrence of vertebrate consumption for the Gracilinanus genus. Bird remnants in the scats consisted of down feathers, bones in which the epiphysis were not yet fully merged to the diaphysis, and eggshells. Thus, this marsupial likely feeds only on eggs and young birds, probably opportunistically and rarely preying upon bird nests.

\section{Relative abundance of consumed food items}

The abundance of arthropods consumed by G. agilis differed between sexes and seasons. According to our expectations, males feed more on arthropods in the cool-dry season in comparison to females. This pattern was also observed in males of G. microtarsus (Martins et al. 2006), which travelled greater distances searching for mates, resulting in greater demand for energy. We also found a higher consumption of invertebrates by reproductive females in comparison to nonreproductive females. A greater demand for energy and protein caused by fetus development and lactation may also result in the more intensive consumption of insects (Payne and Wheeler 1968; Smith and Broome 1992; Metges 2001). This pattern was also observed, for 
Observed $\square$ Expected

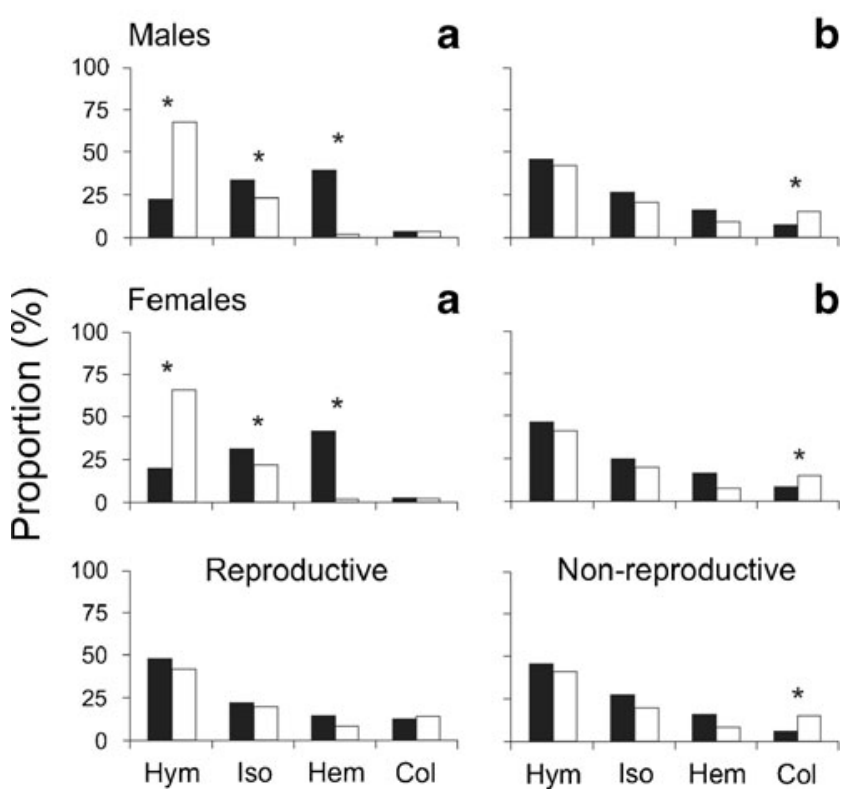

Fig. 2 Frequency of the four most common insect orders (Hym= Hymenoptera, $I s o=$ Isoptera, $\mathrm{Hem}=$ Hemiptera, $\mathrm{Col}=$ Coleoptera) present in scats of G. agilis sampled in four areas (FAL, JB1, JB2, and JB3) of cerradão located in Central Brazil and the expected frequency according to availability in the environment (inferred by the relative invertebrate biomass sampled with pitfall traps). Individuals of G. agilis from the four sampled areas were grouped except for the order Isoptera, for which individuals from one area (JB3) were not considered in the analysis (see text for details). Top and middle figures show comparisons made independently in two seasons of the year ( $a=$ cool-dry season and $b=$ warm-wet season) and for both sexes (sample sizes: Isoptera - 69 males and 72 females in the cool-dry season, 71 males and 145 females in the warm-wet season; remaining orders-90 males and 90 females in the cool-dry season, 82 males and 160 females in the warm-wet season). We also compared reproductive females (Isoptera: $N=50$; remaining orders: $N=62$;) vs. nonreproductive females (Isoptera: $N=95$; remaining orders: $N=98$ ) in the warm-wet season (bottom figure). $* P<0.05$, significant values between pairs of each insect order conducted when the general comparison was significant (chi-square test)

example, in the mountain pygmy possum Burramys parvus (Burramyidae) (Smith and Broome 1992), the vespertilionid bat Myotis daubentoni (Encarnação and Dietz 2006), and the house mouse Mus domesticus (Tann et al. 1991).

Regarding fruit consumption, we found no differences related to sex, season, or female reproductive condition. Contrary to our expectations, fruits were frequent in the diet of this marsupial in both seasons. A potential reduction in the availability of fruit during the dry-cool season (Batalha and Martins 2004) might have been compensated by a more active search for this resource because fruits could represent a relevant source of water during the dry period in cerradão areas (Camargo et al. 2011), where there are no associated watercourses (Ribeiro and Walter 1998).
Frequency of occurrence and selection of arthropod orders

b

We detected distinct patterns of prey selection for the most common arthropod orders. Our findings indicated that $G$. agilis is not a specialist in termites, but these insects are relevant for its diet, especially in the cool-dry season. The congeneric G. microtarsus also feeds more heavily on Isoptera during this season (Martins et al. 2006).

Isopteran insects have large amount of fat (Defoliart 1992) and water (Cooper and Withers 2004). The accumulation of fat in the cool-dry season can be important for G. agilis males that travel longer distances searching for a mate and for females that are pregnant at the end of this season and lactate until the middle of the warm-wet season (Martins et al. 2006). Moreover, the significant amount of water provided by the termites can also be advantageous during the dry season, especially in the cerradão.

Our results revealed an unusually high consumption and positive selection of Hemiptera by G. agilis in the cool-dry season, despite the lower abundance of this resource in relation to the warm-wet season. The only Hemiptera species (Euschistus heros) consumed in the cool-dry season is an agricultural pest that causes damages up to $30 \%$ in the quality and production of soybeans in Brazil (Nunes and Corrêa-Ferreira 2002). In our study area, it is possible that after the soybean harvest in surrounding areas, these insects moved to natural areas, thus increasing their local abundance in such areas. Because E. heros is a phytophagous insect that remains mainly on leaves, its abundance may have been underestimated by our ground pitfalls. Alternatively, G. agilis specifically selected E. heros among the Hemiptera species.

The low abundance of beetles in the environment must directly affect the consumption of this resource. We observed that G. agilis feeds on beetles in the cool-dry season according to their availability in the environment. In contrast to our results, Bocchiglieri et al. (2010) detected a high consumption of beetles ( $76 \%$ of the sampled individuals fed on these insects) by G. agilis in two of our study areas (JB2 and JB3) 8 years before our study. These results might indicate a temporal change in the abundance of this resource.

In the warm-wet season, except for the reproductive females, the other G. agilis individuals did not select any insect order. The consumption of invertebrates according to their availability in the environment could be caused by a greater availability of fruits during this season (Batalha and Martins 2004) combined with the occurrence of a less stressful environment (i.e., greater rainfall and warmer temperatures overnight).

The patterns of insect selection by reproductive females that we detected seemed to reflect a higher energy demand during pregnancy and lactation. These females fed preferentially on ants and beetles when compared to the nonreproductive ones. 
Ants have large amounts of chitin, and such biopolymer can be particularly advantageous for lactating or pregnant females, since a high protein intake is needed for supporting the fetus formation and the production of milk (Payne and Wheeler 1968; Metges 2001). The consumption of beetles could also provide expressive amounts of fat and protein to females during reproduction (Ramos-Elorduy et al. 2006). More insectivorous didelphids present adaptations in their digestive tract that could be related to the metabolization of large amounts of protein (Cáceres 2005). As other mammals do (i.e., bats) (Webb et al. 1993), these marsupials, hypothetically, also may extract carbohydrates from the exoskeleton of insects. Additionally, data for the omnivorous Petaurus breviceps (Diprotodontia, Petauridae) indicated that females might select higher protein dietary items due to reproductive requirements (Smith and Green 1987).

\section{Conclusions}

Our study revealed that although G. agilis is an insectivoreomnivore marsupial, fruits also are a relevant part of its diet. Changes in both intensity and frequency in the consumption of food items seem to be caused mainly by energetic and nutritional requirements related to the reproductive condition of the animals. Although G. agilis opportunistically fed on insect orders that were among the most abundant in the environment (Hymenoptera, Isoptera, Hemiptera, and Coleoptera), there was both positive (for termites and bedbugs) and negative (for ants) selection of these insects during the cool-dry season, whereas in the warm-wet season, this marsupial tended to feed according to the availability of these resources in the environment.

Acknowledgments We thank the Brazilian National Council for Scientific and Technological Development (Conselho Nacional de Desenvolvimento Científico e Tecnológico- $\mathrm{CNPq}$ ) for the graduate scholarship (NFC and JFR), the Research Productivity Grant (EMV, No. 308153/2007-3), and the research funding (No 483117/2009-9) granted during this study. We acknowledge and thank the permission granted by the JBB and FAL to our fieldwork. We are also grateful to the staff of the Laboratory of Vertebrate Ecology of the University of Brasilia (UnB) for the fieldwork assistance.

\section{References}

Abensperg-Traun M, Steven D (1997) Ant- and termite-eating in Australian mammals and lizards: a comparison. Austr J Ecol 22:9-17 Astúa de Moraes D, Santori RT, Finotti R, Cerqueira R (2003) Nutritional and fibre content of laboratory-established diets of Neotropical opossums (Didelphidae). In: Jones M, Dickman C, Archer M (eds) Predators with pouches: the biology of carnivorous marsupials. CSIRO Publishing, Melbourne, pp 229-237
Batalha MA, Martins FR (2004) Reproductive phenology of the cerrado plant community in Emas National Park (central Brazil). Austr J Bot 52:149-161

Belovsky GE (1978) Diet optimization in a generalist herbivore: the moose. Theor Pop Biol 14:105-134

Bocchiglieri A, Mendonça AF, Campos JB (2010) Diet composition of Gracilinanus agilis (Didelphimorphia, Didelphidae) in dry woodland areas of Cerrado in central Brazil. Mammalia $74: 225-227$

Bourlière F (1985) Primate communities: their structure and role in tropical ecosystems. Int J Prim 6:1-25

Cáceres NC (2004) Diet of three didelphid marsupials (Mammalia, Didelphimorphia) in southern Brazil. Mamm Biol 69:430-433

Cáceres NC (2005) Comparative lengths of digestive tracts of seven didelphid marsupials (Mammalia) in relation to diet. Rev Bras Zool 22:181-185

Camargo NF, Cruz RMS, Ribeiro JF, Vieira EM (2011) Frugivoria e potencial dispersão de sementes pelo marsupial Gracilinanus agilis (Didelphidae: Didelphimorphia) em áreas de Cerrado no Brasil central. Act Bot Bras 25:646-656

Cantor M, Ferreira LA, Silva WR, Setz EZF (2010) Potential seed dispersal by Didelphis albiventris (Marsupialia, Didelphidae) in highly disturbed environment. Biota Neotr 10:45-51

Caron L, Garant Y, Bergeron JM (1985) The effect of digestibility values of resources on the reliability of food-habit studies from fecal analyses. Can J Zool 63:2183-2186

Casella J, Cáceres NC (2006) Diet of four small mammal species from Atlantic forest patches in south Brazilian. Neotr Biol Cons 1:5-11

Cooper CE, Withers PC (2004) Termite digestibility and water and energy contents determine the water economy index of numbats (Myrmecobius fasciatus) and other myrmecophages. Physiol Biochem Zool 77:541-650

$\mathrm{R}$ development Core Team (2011) R: a language and environment for statistical computing. R Foundation for Statistical Computing, Vienna, Austria. http://www.R-project.org/. Accessed 17 Dec 2012

Covich AP, Palmer MA, Crowl TA (1999) The role of benthic invertebrate species in freshwater ecosystems: zoobenthic species influence energy flows and nutrient cycling. BioScience 49:119-127

DeFoliart G (1992) Insects as human food: Gene DeFoliart discusses some nutritional and economic aspects. Crop Prot 11:395-399

Eiten G (1972) The Cerrado vegetation of Brazil. Bot Rev 38:201-341

Emmons LH, Feer F (1990) Neotropical rainforest mammals: a field guide. The University of Chicago Press, Chicago

Encarnação JA, Dietz M (2006) Estimation of food intake and ingested energy in Daubenton's bats (Myotis daubentonii) during pregnancy and spermatogenesis. Eur J Wildl Res 52:221-227

García D, Rodríguez-Cabal M, Amico G (2009) Seed dispersal by a frugivorous marsupial shapes the spatial scale of a mistletoe population. J Ecol 93:693-704

Gibson LA (2001) Seasonal changes in the diet, food availability and food preference of the greater bilby (Macrotis lagotis). Wildl Res 28:121-134

Greene HW, Jaksic FM (1983) Food-niche relationships among sympatric predators: effects of level of prey identification. Oikos 40:151-154

Hayward MW, Kerley GIH (2005) Prey preferences of the lion (Panthera leo). J Zool 267:309-322

Hosmer DW, Lemeshow S (1989) Applied logistic regression. Wiley, New York

Jones ME, Barmuta LA (1998) Diet overlap and abundance of sympatric dasyurid carnivores: a hypothesis of competition? J Anim Ecol 67:410-421

Julien-Laferrière D, Atramentowicz M (1990) Feeding and reproduction of three didelphid marsupials in two neotropical forest (French Guiana). Biotropica 22:404-415

Klink CA, Machado RB (2005) A conservação do Cerrado brasileiro. Megadiv 1:147-155 
Lacher TE Jr, Alho CJR (2001) Terrestrial small mammal richness and habitat associations in an Amazon forest-Cerrado contact zone. Biotropica 33:171-181

Leiner NO, Silva WR (2007) Seasonal variation in the diet of the Brazilian slender opossum (Marmosops paulensis) in a montane Atlantic Forest area, southeastern Brazil. J Mamm 88:158-164

Lessa LG, Costa FN (2010) Diet and seed dispersal by five marsupials (Didelphimorphia: Didelphidae) in a Brazilian cerrado reserve. Mamm Biol 75:10-16

Martins EG, Bonato V (2004) On the diet of Gracilinanus microtarsus (Marsupialia, Didelphidae) in an Atlantic rainforest fragment in southeastern Brazil. Mamm Biol 69:58-60

Martins EG, Bonato V, Pinheiro HP, Reis SF (2006) Diet of the gracile mouse opossum (Gracilinanus microtarsus) (Didelphimorphia: Didelphidae) in a Brazilian Cerrado: patterns of food consumption and intra-population variation. J Zool 269:21-28

Metges CC (2001) Does dietary early life affect the development of adiposity in mammals? J Nutr 131:2062-2066

Miranda AC, Miranda HS, Dias IFO, Dias BFS (1993) Soil and air temperatures during provocated cerrado fires in central Brazil. J Trop Ecol 9:313-320

Myers N, Mittermeier RA, Mittermeier CG, Fonseca GAB, Kent J (2000) Biodiversity hotspots for conservation priorities. Nature 403:853-858

Nitikman LZ, Mares MA (1987) Ecology of small mammals in a gallery forest of central Brazil. Ann Carn Mus 56:75-95

Nunes MC, Corrêa-Ferreira BS (2002) Danos causados à soja por adultos de Euschistus heros (Fabricius) (Hemiptera: Pentatomidae), sadios e parasitados por Hexacladia smithii Ashmead (Hymenoptera: Encyrtidae). Neotr Ent 31:109-113

Paglia AP, da Fonseca GAB, Rylands AB, Herrmann G, Aguiar LMS, Chiarello AG, Leite YLR, Costa LP, Siciliano S, Kierulff MCM, Mendes SL, Tavares VC, Mittermeier RA, Patton JL (2012) Lista Anotada dos Mamíferos do Brasil. Conservation International, 2nd edition, Arlington

Payne PR, Wheeler EF (1968) Comparative nutrition in pregnancy and lactation. Proc Nutr Soc 27:129-138

Pinheiro F, Diniz IR, Coelho D, Bandeira MPS (2002a) Seasonal pattern of insect abundance in the Brazilian Cerrado. Aus Ecol 27:132-136

Pinheiro PS, Carvalho FMV, Fernandez FAS, Nessimian JL (2002b) Diet of the marsupial Micoureus demerarae in small fragments of Atlantic Forest in Southeastern Brazil. Stud Neotr Fauna Environ $37: 213-218$

Pulliam HR (1975) Diet optimization with nutrient constraints. Am Nat 109:765-768

Quental TB, Fernandez FAS, Dias AT, Rocha FS (2001) Population dynamics of the marsupial Micoureus demerarae in small fragments of Atlantic Coastal Foretin Brazil. J Trop Ecol 17:339-352

Ramos-Elordy J, Neto CM, Santos EF, Jéssica FS, Moreno JMP, Landero-Torres I, Sergio C, Campos A, Pérez AG (2006)
Estudio comparativo del valor nutritivo de varios coleoptera comestibles de México y Pachymerus nucleorum (Fabricius, 1792) (Bruchidae) de Brasil. INCI 31:512-516

Rawlins DR, Handasyde KA (2002) The feeding ecology of the striped possum Dactylopsila trivirgata (Marsupialia: Petauridae) in far north Queensland. Austr J Zool 257:195-206

Ribeiro JF, Walter BMT (1998) Fitofisionomias do cerrado. In: Sano SM, Almeida SP (eds) Cerrado: ambiente e flora. EMBRAPACPAC, Planaltina-DF, pp 87-166

Ritchie ME (1988) Individual variation in the ability of Columbian ground squirrels to select an optimal diet. Evol Ecol 2:232252

Rossi RV, Bianconi GV, Pedro WA (2006) Ordem didelphimorphia. In: Reis MR, Peracchi AL, Pedro WA, Lima IP (eds) Mamíferos do Brasil. Editora da Universidade Estadual de Londrina, Londrina, pp 27-66

Santori RT, Astúa de Moraes D (2006) Alimentação, nutrição e adaptações alimentares de marsupiais brasileiros. In: Cáceres NC, Monteiro-Filho ELA (eds) Os marsupiais de Brasil: biologia, ecologia e evolução. UFMS, Campo Grande, pp 241-254

Santori RT, Moraes DA, Cerqueira R (1995) Diet composition of Metachirus nudicaudatus and Didelphis aurita (Marsupialia, Didelphoidea) in southeastern Brazil. Mammalia 59:511-516

Smith AP, Broome LS (1992) The effects of season, sex, and habitat on the diet of the mountain pygmy-possum (Burramys parvus). Wildl Res 19:755-768

Smith AP, Green S (1987) Nitrogen requirements of the sugar glider (Petaurus breviceps), an omnivorous marsupial, on a honeypollen diet. Phys Zool 60:82-92

Tann CR, Singleton GR, Coman BJ (1991) Diet of the house mouse, Mus domesticus, in the mallee wheatlands of North-Western Victoria. Wildl Res 18:1-12

Triplehorn CA, Johnson NF (2005) Borror and DeLong's introduction to the study of insects. Thomson Brooks/Cole, Belmont

Vieira EM, Astúa de Moraes D (2003) Carnivory and insectivory in neotropical marsupials. In: Jones M, Dickman C, Archer M (eds) Predators with pouches: the biology of carnivorous marsupials. CSIRO Publishing, Collingwood, pp 267-280

Vieira EM, Izar P (1999) Interactions between aroids and arboreal mammals in the Brazilian Atlantic rainforest. Plant Ecol 145:75-82

Vieira EM, Port D (2007) Niche overlap and resource partitioning between two sympatric fox species in southern Brazil. J Zool 272:57-63

Webb PI, Speakman JR, Racey PA (1993) Defecation, apparent absorption efficiency, and the importance of water balance in captive brown long-eared (Plecotus auritus) and Daubenton's (Myotis daubentoni) bats. J Zool 230:619-628

Westoby M (1974) An analysis of diet selection by large generalist herbivores. Am Nat 108:290-304 